\title{
Article \\ Antioxidant Activity and Bioactive Compounds of Lamium album Flower Extracts Obtained by Supercritical Fluid Extraction
}

\author{
Pascaline Aimee Uwineza ${ }^{1, *}$, Anna Gramza-Michałowska ${ }^{2} \mathbb{D}$, Marcin Bryła ${ }^{3}$ and $^{\text {Agnieszka Waśkiewicz }}{ }^{1}(\mathbb{D}$ \\ 1 Department of Chemistry, Poznań University of Life Sciences, Wojska Polskiego 75, 60-625 Poznań, Poland; \\ agat@up.poznan.pl \\ 2 Department of Gastronomy Science and Functional Foods, Poznań University of Life Sciences, \\ Wojska Polskiego 31, 60-624 Poznań, Poland; anna.gramza@up.poznan.pl \\ 3 Department of Food Safety and Chemical Analysis, Institute of Agricultural and Food Biotechnology, \\ 02-532 Warsaw, Poland; marcin.bryla@ibprs.pl \\ * Correspondence: pascaline.uwineza@up.poznan.pl
}

Citation: Uwineza, P.A.

Gramza-Michałowska, A.; Bryła, M.; Waśkiewicz, A. Antioxidant Activity and Bioactive Compounds of Lamium album Flower Extracts Obtained by Supercritical Fluid Extraction. Appl. Sci. 2021, 11, 7419. https://doi.org/ 10.3390/app11167419

Academic Editor: Nina Kashchenko

Received: 20 July 2021

Accepted: 9 August 2021

Published: 12 August 2021

Publisher's Note: MDPI stays neutral with regard to jurisdictional claims in published maps and institutional affiliations.

Copyright: (c) 2021 by the authors. Licensee MDPI, Basel, Switzerland. This article is an open access article distributed under the terms and conditions of the Creative Commons Attribution (CC BY) license (https:/ / creativecommons.org/licenses/by/ $4.0 /)$.

\begin{abstract}
In this research, supercritical $\mathrm{CO}_{2}$ extraction is applied to extract bioactive compounds from Lamium album (white dead nettle, Lamiaceae). Extraction was performed at various temperatures (40, 50 , and $60^{\circ} \mathrm{C}$ ) using methanol as co-solvent at a constant flow rate of $\mathrm{CO}_{2}$, methanol, and pressure. The collected extracts were characterized in terms of antioxidant capacity by using DPPH, ABTS and FRAP in vitro antioxidant activity assays, whereas the Folin-Ciocalteu procedure was employed to estimate the total phenols content (TPC). On the other hand, phenolic compounds in the extracts were quantitated by liquid chromatography coupled with a photodiode array detector (UPLC-PDA) and confirmed with a mass detector (TQD). The extracts have shown high TPC ranged between 234.17 to $650.17 \mathrm{mg} \mathrm{GAE} / \mathrm{g}$ extract. DPPH scavenging of the extracts was estimated and obtained EC50 values ranged from 0.12 to $0.37 \mathrm{mg} / \mathrm{mL}$ of solution. The ABTS radical scavenging activity ranged from 43.20 to $44.53 \mu \mathrm{g} \mathrm{TE} / \mathrm{g}$. The FRAP value was found within the range of 19.48 to $44.74 \mu \mathrm{mol} \mathrm{TE} / \mathrm{g}$ of extract. Differences between extraction conditions were observed. In this research, $50{ }^{\circ} \mathrm{C} / 250$ bar was efficient for the TPC, DPPH, ABTS, and FRAP assays; moreover, statistically, TPCs and FRAP assay showed significant differences between the conditions at $\alpha=0.05$. The identification of phenolic compounds in the obtained extract of Lamium album flowers, using UPLC/PDA, revealed that chrysin, pinostrobin, myricetin, and trans-3-hydroxycinnamic acid were the significant molecules present, which may be responsible for the high content of polyphenols and antioxidant activity. The results obtained indicated that $\mathrm{SC}-\mathrm{CO}_{2}$ could be considered an alternative method for extracting bioactive compounds of Lamium album. High antioxidant activity and the presence of various bioactive compounds indicate the potential of this plant from the Lamiaceae family and the possibility of its application in various industries, including agriculture, food technology, or pharmacy.
\end{abstract}

Keywords: white dead nettle; polyphenols; bioactive compounds; antioxidant assays; TPC; DPPH; ABTS; FRAP; supercritical fluid extraction; UPLC/PDA

\section{Introduction}

Plants have been used by humans as both food and medicine since prehistoric times. Currently, there is an interest in the use of bioactive compounds, especially polyphenols, derived from plant materials in food preservation, pharmaceuticals, cosmetics, and natural pesticides. These bioactive compounds can play a preventive or supportive role in the treatment of various metabolic disorders and diseases due to their antioxidant, antimicrobial, anticancer, and anti-inflammatory properties [1]. Lamium album, widely known as nonsting nettle or white dead nettle, is a perennial herbaceous plant with white blooms that is inherent to Europe, Western Asia, and North Africa [2]. It belongs to the Lamiaceae family, which is recognized for producing plant species high in different bioactive compounds that generally differ in structures, biological properties, and mechanisms of action. 
Furthermore, the genus Lamium contains nearly 40 species; among them, the Lamium album is the most widely distributed species [3]. It has a wide variety of biological activities due to its various phytochemicals such as iridoids, flavonoids, triterpenes, fatty acids, polysaccharides, saponines, phytoecdysteroids, phenolic acids, amines, essential oils, tannins, and mucilage [4]. Flowers and leaves of the Lamium album are considered food for humankind [2]. They can be eaten raw or cooked. It is also used in teas, dietary supplement products, and its intake is primarily connected with its health benefits [2,5]. The dried flowers of this plant have demonstrated uterotonic, astringent, antispasmodic, and anti-inflammatory activities and consequently are used in menorrhagia, uterine hemorrhage, vaginal and cervical inflammation, and leukorrhea treatment [3,6]. Additionally, L. album flowers have been reported to possess antioxidant, free radical scavenging, and antiproliferative properties [3]. Nowadays, the beneficial understanding of natural products has been substantially increased and scientifically proven, allowing a better grasp of their valuable features. Therefore, a significant quantity of information regarding the efficacy of L. album extracts and raw material has been accumulated, and several health-related benefits have been successfully verified. Various studies in vivo or in vitro of Lamium album extracts (methanol, ethyl acetate and heptane, butanol, ethanol, and chloroform) have been done, and their antioxidant, cytoprotective, anticancer, antiviral, antimicrobial, and antiproliferative activities have been reported [5,7-9]. Additionally, bioactive phenolic compounds of this plant were also studied, and the results have shown that the crucial compounds mainly include; phenylpropanoid verbascoside, isoscutellarein derivatives, and isoverbascoside, some phenolic acids such as caffeic acid, ferulic acid, syryngic acid, and flavonoids $[4,5]$. Various conclusions from the mentioned studies have shown a possible correlation between phenolic compounds and the antioxidant activity of this plant and its natural health benefits [8].

Despite all of the positive attributes claimed to the Lamium album, there are very few publications on L. album, and the data are incomplete. It is vital to carefully study the properties of this plant using modern techniques, including advanced techniques for bioactive extraction such as ultrasound, pulsed electric field, extrusion, microwave heating, ohmic heating, supercritical fluids, and accelerated solvents as they improve the quantity, quality, and selectivity of bioactive components extracted from plant matrix [10] and advanced analytical techniques for identifying and quantitating different bioactive components such as ultrahigh-performance liquid chromatography with photodiode array or/and mass spectrometer (UPLC/PDA or LC/MS/MS), gas chromatography, etc., which have been claimed to be cost-effective, repeatable, accurate, linear, precise, and resilient. However, no unique extraction method is recognized to be the best one for extracting bioactive compounds from plants due to their diversity. Therefore, to optimize the qualitative and quantitative properties of the bioactive compounds, the selection of an appropriate extraction technique and conditions are critical [11].

Supercritical fluid extraction (SFE) is an advanced and environmentally friendly technique used to extract bioactive compounds from different materials. Supercritical $\mathrm{CO}_{2}$ $\left(\mathrm{SC}-\mathrm{CO}_{2}\right)$ is one of the most often used supercritical solvents due to its good features, including non-toxic, cheap, non-explosive, and mild critical conditions (critical temperature $31.7^{\circ} \mathrm{C}$ and critical pressure approximately 73.8 bar) [12]. Moreover, $\mathrm{SC}-\mathrm{CO}_{2}$ has physicochemical qualities that are intermediate between those of a liquid and a gas, with low viscosity, high density, and diffusivity that allow it to be an excellent alternative to traditional extraction technologies [13]. This technique can be used for a broad spectrum of chemical and biochemical extraction processes [14] because of its selectivity property, which can be adjusted by minor changes in pressure and/or temperature. SC- $\mathrm{CO}_{2}$ produces excellent extracts with yields that are equivalent to those made using organic solvent extraction. Some results have shown the highest antioxidant and antifungal properties of SC- $\mathrm{CO}_{2}$ extract compared to the conventional method $[15,16]$. In addition to these, $\mathrm{CO}_{2}$ has the benefit of being appropriate for extracting thermo-labile chemicals since it does not require extensive solvent heating. However, one of the limitations of this technique is 
that $\mathrm{CO}_{2}$ is a non-polar solvent and may not be effective alone to extract polar compounds such as phenolics. As a result, there is an application of methanol, water, or ethanol as co-solvent or modifier to enhance the solvation power of $\mathrm{SC}-\mathrm{CO}_{2}$, improve its affinity for poorly soluble solutes (alkaloids, phenolics, and glycosidic compounds), increase solubility, as well as the extraction yield with respect to operating pressure and temperature [13].

The basic goals of this research were to extract the dried Lamium album flower by using $\mathrm{SC}-\mathrm{CO}_{2}$ with methanol as co-solvent, to investigate in vitro antioxidant capacity of these extracts using different radical scavenging assays (DPPH and ABTS), reducing power assay (FRAP), total phenols estimation using Folin-Ciocalteu, and phenolic compounds quantitation by using UPLC-PDA (Waters, Manchester, MA, USA). This approach should complement the previously known extraction techniques of the Lamium album and improve the dissemination of this green technology and the possibility of using Lamium album flower extract in agriculture, food, cosmetics, and pharmaceutical industries.

\section{Materials and Methods}

\subsection{Plant Material}

High-quality of dried Lamium album flowers were collected from ecological area (Podlasie) in Poland and certified by herbal company Dary Natury.

\subsection{Chemicals}

Carbon dioxide $\left(\mathrm{CO}_{2}, \mathrm{SFE}\right.$ grade), contained in a dip tube cylinder, was purchased from Air Products Sp, Poland. Methanol for HPLC-super gradient were purchased from POCh (Gliwice, Poland), Folin-Ciocalteu's reagent, and hydrochloric acid 35-38\% purity was purchased from Chempur (Piekary Ślaskie, Poland). Glacial acetic acid, 3,4,5-trihydroxybenzoic acid (gallic acid), and 2,2-dyphenyl-1-picrylhydrazyl (DPPH), iron (III) chloride, sodium acetate, sodium carbonate anhydrous, potassium acetate, phosphate buffered saline tablet, potassium persulphate, 2,4,6-tris(2-pyridyl)-s-triazine (TPTZ), and 2,2'-azino-bis(3-ethylbenzothiazoline)-6-sulphonic acid (ABTS) were purchased from Sigma-Aldrich (St. Louis, MO, USA). All phenolic standards including trans-ferulic acid, trans-cinnamic acid, trans-hydroxycinnamic acid, syringic acid, synapic acid, vanillic acid, p-coumaric acid, caffeic acid, caffeic acid phenethyl ester (CAPE), kaempherol, quercetin, (+)-catechin, (-)-epicatechin, apigenin, rutin, myricetin, pinocenbrin, pinobanksin, pinostrobin, galangin, chrysin, and naringenin were purchased from Sigma-Aldrich (St. Louis, MO, USA). All chemicals were of analytical grade.

\subsection{Supercritical Carbon Dioxide $\left(\mathrm{SC}-\mathrm{CO}_{2}\right)$ Extraction}

The extraction process was carried out on a laboratory scale by using MV-10ASFE (Waters, Manchester, MA, USA) consisted of a $\mathrm{CO}_{2}$ cylinder and a cooling system, fluid delivery module, column oven, back pressure regulator, heat exchanger and fraction collection module with ChromScope v1.20 software (Waters, Manchester, MA, USA). Then, $2 \mathrm{~g}$ of Lamium album flower was kept in the extraction vessel of $25 \mathrm{~mL}$ and placed in the oven set at the desired different temperatures $\left(40,50\right.$ and $60^{\circ} \mathrm{C}$ ) and pressure (250 bar). The $\mathrm{CO}_{2}$ flow rate was $4 \mathrm{~mL} / \mathrm{min}$, and methanol was fixed at $1 \mathrm{~mL} / \mathrm{min}$. Once the set temperature and pressure (at solvent pumps and back pressure regulator) were achieved after turning on the injection valve and the system was in equilibrium, the extraction was carried out for $180 \mathrm{~min}$ in each experimental run, which was composed (based on the trial experiments) of 1st dynamic time $45 \mathrm{~min}$, static time $15 \mathrm{~min}$ and 2 nd dynamic time of $120 \mathrm{~min}$. Lamium album extracts were collected in flasks placed in a fraction collection module, and it was stored at $-20^{\circ} \mathrm{C}$ before further analysis of polyphenols and antioxidant activity.

\subsection{Quantification of Total Phenolic Compounds}

Total phenolic content (TPC) of Lamium album extract was estimated spectrophotometrically according to the Folin-Ciocalteu method by following the protocol of Arabshahi- 
Delouee and Urooj (2007) [17] with minor modifications. Gallic acid (50-500 mg/mL) [18] was used for the standard calibration curve and distilled water as a blank sample. In a test tube, $1.60 \mathrm{~mL}$ of distilled water were mixed with $20 \mu \mathrm{L}$ of samples, blank or standard to be analyzed. $100 \mu \mathrm{L}$ of Folin-Ciocalteu reagent was then directly added and vortexed. After $3 \mathrm{~min}, 300 \mu \mathrm{L}$ of $75 \mathrm{~g} / \mathrm{L} \mathrm{Na}_{2} \mathrm{CO}_{3}$ was added and mixed toughly. The obtained solution was incubated at room temperature for $45 \mathrm{~min}$ in absence of light after which absorbance readings were taken at $760 \mathrm{~nm}$ using a Varian Cary 300bio UV-VIS spectrophotometer (Agilent, Santa Clara, CA, USA). All measurements were performed at least in triplicate and the total phenolic content estimation was calculated by using this formula according to Mabrouki et al. (2018) [19]:

$$
\mathrm{TPC}=(\mathrm{c} \times \mathrm{v}) / \mathrm{m}
$$

where $\mathrm{c}$ is the concentration of gallic acid established from the calibration curve $(\mathrm{mg} / \mathrm{mL})$, $\mathrm{v}$ is the volume of extract solution $(\mathrm{mL})$ and $\mathrm{m}$ is the weight of the sample extract $(\mathrm{g})$. the results were expressed as $\mathrm{mg}$ gallic acid equivalent per gram of the extract (mg GAE/g of extract).

\subsection{Evaluation of Antioxidant Activity}

\subsubsection{DPPH Assay}

2,2-Diphenyl-1-picrylhydrazyl radical ( $\mathrm{DPPH}^{\bullet}$ ) scavenging capacity assay is a decolorization assay that directly measures the scavenging capacity of antioxidants with DPPH radicals by monitoring its absorbance at $517 \mathrm{~nm}$ with a spectrophotometer [20].

The free radical scavenging activity of Lamium album extract was measured by DPPH assay according to the method described by Moradi et al. (2016) [21] with minor modifications. The working solution was prepared by making a methanolic solution of DPPH (0.1 mM). A $2850 \mu \mathrm{L}$ of this solution was mixed with $150 \mu \mathrm{L}$ of the sample, standard (Trolox) at different concentrations or blank (methanol). The reaction mixture was shaken well and incubated in the dark for $30 \mathrm{~min}$ at room temperature. After this time, the absorbance was taken at $517 \mathrm{~nm}$ using Varian Cary 300bio UV-VIS spectrophotometer (Agilent, Santa Clara, CA, USA). Low absorbance of the reaction mixture indicated high free radical scavenging activity. The experiment was carried out in triplicate, and the results are average values. The scavenging activity was estimated based on the percentage of DPPH radical scavenged as the following equation:

$$
\mathrm{DPPH}^{\bullet} \text { inhibition } \%=(\mathrm{Ab}-\mathrm{As}) / \mathrm{Ab} \times 100
$$

where $\mathrm{Ab}$ is the absorbance of the blank and As is the absorbance of the sample. The EC50 value, the amount of antioxidant necessary to halve the initial DPPH concentration, was estimated using linear regression of plots of DPPH radical inhibition percentages versus the concentrations of the tested extracts of Lamium album flowers. The results were used for comparing the quality of the antioxidant extracts. The experiment was repeated three times at each concentration.

\subsubsection{ABTS Assay}

The assay estimates the capacity of antioxidants to scavenge the stable radical cation $\mathrm{ABTS}^{+}$(2,2'-azinobis (3- ethylbenzothiazoline-6-sulphonic acid). Antioxidant activity was determined with the modified method proposed by Re et al., 1999 [22], where the bluegreen color of $\mathrm{ABTS}^{+} \bullet$ was decreased in the presence of antioxidants. The $\mathrm{ABTS}^{+}$radical was prepared by mixing equal amounts of two stock solutions (7 mM ABTS solution and $2.45 \mathrm{mM}$ potassium persulfate solution) and allowing them to react for $16 \mathrm{~h}$ at room temperature in the dark. The working solution was then prepared by mixing $3.9 \mathrm{~mL}$ of $\mathrm{ABTS}^{+}$with $140 \mathrm{~mL}$ of $5 \mathrm{mM}$ phosphate buffered-saline ( $\mathrm{pH}$ 7.4) to obtain an absorbance of $(0.70 \pm 0.02)$ at $734 \mathrm{~nm}$ using the spectrophotometer. Fresh $\mathrm{ABTS}^{+\bullet}$ working solution was prepared daily. Then, $2850 \mu \mathrm{L}$ of $\mathrm{ABTS}^{+}$working solution were allowed to react with $150 \mu \mathrm{L}$ of plant extracts in a test tube for $8 \mathrm{~min}$ in water bath incubation at $30^{\circ} \mathrm{C}$. The 
absorbance was measured at $734 \mathrm{~nm}$ using a Varian Cary 300bio UV-VIS spectrophotometer (Agilent, Santa Clara, CA, USA). Trolox was used as standard, PBS as the blank. The results are expressed in $\mu \mathrm{g}$ Trolox equivalents/g of extract mass $(\mu \mathrm{g}(\mathrm{TE}) / \mathrm{g})$ on the basis of the calibration curve according to the following formula:

$$
\text { ABTS value }(\mu \mathrm{g} \text { TE/g of extract })=(c \times v) / m
$$

where $\mathrm{c}$ is the Trolox concentration $(\mu \mathrm{g} / \mathrm{mL})$ of the corresponding standard curve of the plant extract, $\mathrm{v}$ is the sample volume $(\mathrm{mL})$, and $\mathrm{m}$ is the weight of the plant extract $(\mathrm{g})$ [23].

\subsubsection{Ferric Reducing Antioxidant Power (FRAP) Assay}

The ferric reducing power of Lamium album extract was determined using a modified version of the FRAP assay [24]. This method is based on the reduction of a colored pale yellow ferric complex ( $\mathrm{Fe}^{3+}$-tripyridyl triazine) to a blue-colored ferrous complex $\left(\mathrm{Fe}^{2+}\right.$ tripyridyl triazine) by the action of electron-donating antioxidants at low $\mathrm{pH}$. The working FRAP reagent was prepared daily by mixing $10 \mathrm{~mL}$ of $300 \mathrm{mM}$ acetate buffer of $3.6 \mathrm{pH}$, with $1 \mathrm{~mL}$ of $10 \mathrm{mM}$ TPTZ (2,4,6-tri(2-pyridyl)-s-triazine) in $40 \mathrm{mM}$ hydrochloric acid and with $1 \mathrm{~mL}$ of $20 \mathrm{mM}$ ferric chloride. The reaction mixture was incubated for $15 \mathrm{~min}$ at $37^{\circ} \mathrm{C}$ in a water bath before used. Then, $3 \mathrm{~mL}$ of freshly prepared FRAP reagent was added to $100 \mu \mathrm{L}$ of sample solutions or standard (Trolox) and incubated for $5 \mathrm{~min}$ at $37^{\circ} \mathrm{C}$ in a water bath before analysis. Then, the absorbance of the samples was measured at $593 \mathrm{~nm}$ by using Varian Cary 300bio UV-VIS spectrophotometer (Agilent, Santa Clara, CA, USA). All measurements were carried out in triplicate. The results were expressed as the FRAP value calculated into $\mu \mathrm{mol} / \mathrm{L}$ Trolox on the calibration curve, which was prepared using a methanolic solution of Trolox at the concentration 150-3000 $\mu \mathrm{mol} / \mathrm{L}$. The following formula was used:

$$
\text { FRAP value }=(\mathrm{AS} / \mathrm{AC}) \times 2 \text { concentration of standard }(\mu \mathrm{mol} / \mathrm{L})
$$

where AS is absorbance of the sample and AC is the absorbance of the standard (Trolox) at $593 \mathrm{~nm}$ and concentration of Trolox $(\mu \mathrm{mol} / \mathrm{L})$. From the obtained FRAP value, the final antioxidant activity in each sample was expressed as Trolox equivalents (TE) in terms of $\mu \mathrm{mol} \mathrm{TE} / \mathrm{g}$ extract, and the following equation according to Tomasina et al. (2012) [25] was employed:

$$
\text { AA }(\mu \mathrm{mol} \text { TE } / \mathrm{g} \text { extract })=\text { Trolox }(\mu \mathrm{mol} / \mathrm{L}) / \text { sample }(\mathrm{g} / \mathrm{L})
$$

\subsection{Quantitative Analysis of Polyphenols Using UPLC-PDA}

The concentrations of bioactive compounds in the methanolic extracts were determined using a UPLC-PDA-TQD system, which consisted of the Acquity UPLC chromatograph (Waters, Manchester, MA, USA) coupled with a photodiode detector (PDA e $\lambda$ Detector) (Waters, Manchester, MA, USA) and an electrospray ionization (ESI) triple quadrupole mass spectrometer (TQD) (Waters, Manchester, MA, USA). Mobile phase consisted of two solutions: line $\mathrm{A}-$ water containing $0.1 \% \mathrm{HCOOH}$ and line $\mathrm{B}$ methanol containing $0.1 \% \mathrm{HCOOH}$. The phenolics were separated at $30{ }^{\circ} \mathrm{C}$ on the analytical columna Waters ACQUITY UPLC BEH C18 $(150 \times 2.1 \mathrm{~mm} / \mathrm{ID}$, with $1.7 \mu \mathrm{m}$ particle size) (Waters, Manchester, MA, USA) with flow rate $0.35 \mathrm{~mL} / \mathrm{min}$ and using gradient elution: from 10 to $60 \%$ of B line during $15 \mathrm{~min}$ followed by the return to the initial conditions. Temperature of samples in the autosampler was $10^{\circ} \mathrm{C}$. UV spectral data for all peaks were recorded in the range of 190-450 nm. Data processing was done using Empower 3 (Waters, Manchester, MA, USA). All samples of Lamium album extracts were filtered through a $0.20 \mu \mathrm{m}$ syringe filter (Chromafil, Macherey-Nagel, Duren, Germany) before analyses and were injected to the chromagraphic system in triplicate. Identification of bioactive compounds was done using matching retention times, UV and mass spectra (MRM) data of standards. 


\subsection{Statistical Analysis}

The experimental data were statistically evaluated using the Statgraphics 4.1 software package (Graphics Software System, STCC, Inc., Rockville, MD, USA). A one-way ANOVA was used to assess the significance of the differences between the antioxidant activity and polyphenols concentration in the tested extracts. Fisher's Least Significant Difference (LSD) test at $\alpha=0.05$ was used for the paired tests.

\section{Results and Discussion}

\subsection{Total Phenolic Content}

The use of an environmentally friendly, modern extraction technique (SFE) allowed obtaining pure fractions collected at different temperatures. Supercritical $\mathrm{CO}_{2}$ is a nonpolar solvent, but its polarity can be modified by temperature and pressure variations. Polyphenols with high molecular mass are hardly soluble in pure $\mathrm{CO}_{2}$, but their solubility can be enhanced by adding a polar co-solvent or increasing pressure [26]. In our research, methanol commonly used for extraction and high pressure (250 bar) were used. Testing the antioxidant activity allowed us to check the differences between fractions obtained at different temperatures. The TPCs of the extracts obtained from dry Lamium album flower by SC- $\mathrm{CO}_{2}$ with methanol as co-solvent were determined quantitatively using a spectrophotometric method with Folin-Ciocalteu reagent as the most and commonly used method for total phenols estimation. A calibration curve was established with gallic acid as standard at different concentrations. The results were expressed in $\mathrm{mg}$ of gallic acid equivalent (GAE)/g of extract. All measurements were taken in triplicate, and mean values were calculated. The results of determination of the polyphenols are presented in Table 1.

Table 1. Total phenolic content of Lamium album flower for extracts obtained at different variants of extraction.

\begin{tabular}{ll}
\hline Extraction Conditions & TPC (mg GAE/g of Extract) \\
\hline $40{ }^{\circ} \mathrm{C}$ & $234.17^{\mathrm{a}} \pm 2.48$ \\
$50{ }^{\circ} \mathrm{C}$ & $650.17^{\mathrm{b}} \pm 3.86$ \\
$60^{\circ} \mathrm{C}$ & $418.50^{\mathrm{c}} \pm 2.92$ \\
\hline
\end{tabular}

Values are mean \pm s.d., $n=3$, values with the same lowercase letters in the same column indicate no significant difference at level of $5 \%(p<0.05)$.

As shown in Table 1, the results varied from 234.17 to $650.17 \mathrm{mg} \mathrm{GAE} / \mathrm{g}$ of extract for the studied conditions, which represent a variation of approximately three folds. The extract at $50{ }^{\circ} \mathrm{C}$ showed the highest TPCs of $650.17 \mathrm{mg} \mathrm{GAE} / \mathrm{g}$ of extract, followed by $60{ }^{\circ} \mathrm{C}$, which showed $418.50 \mathrm{mg} \mathrm{GAE} / \mathrm{g}$ of extract, and $40^{\circ} \mathrm{C}$ showed the lowest value of $234.17 \mathrm{mg} \mathrm{GAE} / \mathrm{g}$ of extract. All studied conditions showed a considerable amount of total phenols and they were significantly different as expected due to the effect of temperature on the density and selectivity of the solvent during $\mathrm{SC}-\mathrm{CO}_{2}$. However, a degradation effect may be suspected between $50{ }^{\circ} \mathrm{C}$ and $60^{\circ} \mathrm{C}$ at 250 bar during the extraction process, which has caused a decrease in TPCs.

The total phenolic content obtained in this work is not directly comparable to other studies of Lamium album extracts because the extraction methods are different. In the previously published papers, most of them have used solvent extraction methods to extract Lamium album. Matkowski and Piotrowska (2006) [27] reported $192 \mathrm{mg}$ GAE/g of extract of TPC in methanolic extract of Lamium album, Pereira et al. (2012) [5] reported $500.7 \pm 50.0 \mathrm{mg} / \mathrm{g}$ of extract of phenolic compounds in the ethanolic extract of L. album [5], also other species of Lamium have been reported to have high content of polyphenols $[7,27,28]$ and methanol have been reported as a good solvent [28]. The high TPC value obtained for our extract (especially for the fraction at $50{ }^{\circ} \mathrm{C}$ ) compared to the research of other authors indicates a very effective extraction using the SFE technique. 


\subsection{Antioxidant Activity Determination}

An antioxidant is any chemical that, when present at lower concentrations than those of an oxidizable substrate, considerably slows or inhibits its oxidation. Natural antioxidants and their health advantages have received a lot of attention in recent years. Antioxidant-based medication compositions are used to prevent and cure a wide range of diseases and ailments. Plants are a significant source of natural antioxidants; they produce a diverse spectrum of secondary metabolites with antioxidative activity and therapeutic potential [29]. The antioxidative activity are mostly based on two reaction mechanisms such as hydrogen atom transfer (HAT) and single electron transfer (SET) [30].

Currently, there is no unique method that has been standardized for antioxidant activity determination due to the various reaction features, mechanisms as well as variable phase localizations that are frequently involved in the process [30]; however, while extracting valuable bioactive compounds from various plants, it is very important to select the appropriate method and optimize the extraction conditions, since this has a direct impact on the production of extracts with high activity. In this study, the assessment of antioxidant activity of Lamium album flower extract was conducted by two free radical-scavenging methods, the DPPH free radical scavenging assay and the ABTS radical cation decolorization assay; and by ferric reducing antioxidant power assay (FRAP) in order to have a better estimation on the antioxidant capacity of the Lamium album extract. These assays were conducted using a UV-VIS spectrophotometer.

The antioxidant activity of the sample extracts was examined, and the findings were slightly different. However, all of the assays could be used to determine the antioxidant activity of Lamium album flower extract obtained by $\mathrm{SC}-\mathrm{CO}_{2}$ with methanol as a co-solvent because they all yielded similar rankings among the extracts and demonstrated that extracting the antioxidants at $50{ }^{\circ} \mathrm{C}$ and 250 bar was the best condition in this study. The results are summarized in Table 2.

Table 2. Antioxidant activities estimated by DPPH, ABTS and FRAP assays of extracts from dry Lamium album flowers extracted using $\mathrm{SC}-\mathrm{CO}_{2}$ and methanol as co-solvent.

\begin{tabular}{llll}
\hline $\begin{array}{l}\text { Extraction } \\
\text { Conditions }\end{array}$ & $\begin{array}{l}\text { DPPH EC50 } \\
(\mathbf{m g} / \mathbf{m L})\end{array}$ & ABTS $(\boldsymbol{\mu g}$ TE/g) & FRAP $(\mu \mathrm{mol}$ TE/g of Extract) \\
\hline $40^{\circ} \mathrm{C}$ & $0.37^{\mathrm{a}} \pm 0.04$ & $43.20^{\mathrm{a}} \pm 0.20$ & $19.48^{\mathrm{a}} \pm 0.05$ \\
$50^{\circ} \mathrm{C}$ & $0.12^{\mathrm{b}} \pm 0.00$ & $44.53^{\mathrm{b}} \pm 0.02$ & $44.74^{\mathrm{b}} \pm 0.07$ \\
$60^{\circ} \mathrm{C}$ & $0.16^{\mathrm{b}} \pm 0.00$ & $44.52^{\mathrm{b}} \pm 0.02$ & $28.32^{\mathrm{c}} \pm 0.12$ \\
\hline
\end{tabular}

Values are mean \pm s.d., $n=3$, values with the same lowercase letters in the same column indicate no significant difference at level of $5 \%(p<0.05)$.

\subsubsection{DPPH Scavenging}

This approach has been introduced for the 1st time by Blois (1958) [31], and now is one of the commonly used to assess the free radical scavenging activity of various antioxidant compounds due to its accuracy [32] and it is known to give reliable information concerning the antioxidant ability of the tested compounds. It is based on the reduction of DPPH in alcoholic solutions (methanol or ethanol) in the presence of a hydrogen-donating antioxidant. The dark violet color of the DPPH radical becomes yellowish or colorless due to the antioxidant compound, causing a decrease in the absorbance at $517 \mathrm{~nm}[33,34]$. Table 2 showed that the DPPH EC50 results varied from 0.12 to $0.37 \mathrm{mg} / \mathrm{mL}$, which is the quantity of antioxidant required to reduce the initial DPPH radical concentration by $50 \%$ [20]. The lower the value, the higher the antioxidant activity. The overall results showed that the extract obtained at $50^{\circ} \mathrm{C}$ had the highest ability to scavenge the DPPH radical. However, the conditions $50{ }^{\circ} \mathrm{C}$ and $60{ }^{\circ} \mathrm{C}$ were not significantly different at $p$-value $=0.05$.

In similar studies, Paduch et al. (2007) [8] with solvents extraction, has reported free radical scavenging activity of methanol and ethyl acetate extracts of Lamium album, compared to Trolox and their results showed that methanol extract had free radical scav- 
enging properties and an average EC50 of $0.4659 \pm 4.4 \mathrm{mg} / \mathrm{mL}$ while ethyl acetate extracts did not exhibit DPPH radical reduction activity [8]. Additionally, Bubueanu et al. (2013) demonstrated DPPH free radical scavenging activity of butanolic extract of Lamium album in EC50 value to be $19.29 \mathrm{mg} / \mathrm{mL}$ [7].

Furthermore, the antioxidant tests were performed using the scavenging activity of the synthetic stable 1,1-diphenyl-2-picrylhydrazyl (DPPH) free radical and two oxygen radicals spontaneously produced in the cells-superoxide radicals and hydroxyl radicals, both of which are hazardous to the cell at high levels. In comparison to reference compounds like vitamin $\mathrm{E}$ and quercetin, the aqueous component of L. album hydro-alcoholic extract demonstrated modest antioxidant activity. However, among all examined aqueous fractions from 16 medicinal plants, the extract from L. album shown a considerable scavenging impact on DPPH radicals (EC50 $=0.28 \mathrm{mg} / \mathrm{mL}$ ) [35].

\subsubsection{ABTS Assay}

This method was developed by Miller and Rice-Evans [36]. It is based on the scavenging ability of antioxidants to the ABTS radical and it can be used to analyze both hydrophilic and hydrophobic antioxidant capacities of extract [30]. Table 2 in this study shows that ABTS radical scavenging activities of Lamium album extracts varied from 43.20 to $44.53 \mu \mathrm{g} \mathrm{TE} / \mathrm{g}$. The extract at $50{ }^{\circ} \mathrm{C}$ showed the highest antioxidant capacity $(44.53 \mu \mathrm{g} \mathrm{TE} / \mathrm{g})$, followed by $60^{\circ} \mathrm{C}$ which showed a very similar value- $44.52 \mu \mathrm{g}$ TE/g and at $40{ }^{\circ} \mathrm{C}$ was the lowest $-43.20 \mu \mathrm{g}$ TE/g. Statistical analysis has shown a significant difference of the extract at $40{ }^{\circ} \mathrm{C}$ to the other two remainders.

\subsubsection{FRAP Assay}

This method has been developed by Benzie and strain (1996) [30]. It is based on the reduction of ferric ions $\left(\mathrm{Fe}^{3+}\right)$ to ferrous ions $\left(\mathrm{Fe}^{2+}\right)$ by an antioxidant under acidic solution to maintain iron solubility [24,30]. The ferric salt solution is a pale-yellow color, but when reduced to the ferrous form, this changes to blue, and absorbance at $593 \mathrm{~nm}$ increases. However, this method is not convenient to the compounds that act as radical quenching or hydrogen transfer, particularly thiols and protein, and it does not react with glucose and fructose $[20,24]$.

Table 2 shows that the ferric reducing potential of Lamium album extracts varied significantly $(p=0.05)$ from 19.48 to $44.74 \mu \mathrm{mol}$ TE/g of extract, which represents a variation of twofolds. The extract at $50{ }^{\circ} \mathrm{C}$ showed very strong ferric ion reducing activities $44.74 \mu \mathrm{mol} \mathrm{TE} / \mathrm{g}$ of extract, followed by $60^{\circ} \mathrm{C}$ which showed $28.32 \mu \mathrm{mol} \mathrm{TE} / \mathrm{g}$ of extract and $40{ }^{\circ} \mathrm{C}$ showed the lowest value of $19.48 \mu \mathrm{mol} \mathrm{TE} / \mathrm{g}$ of extract. Furthermore, the reducing power of plant extracts by FRAP assay have been reported in various studies [37-39].

In similar studies, Dudenno et al. (2009) [38] investigated antioxidant activities and the total phenolic content of 30 commonly used plants using DPPH, ABTS, FRAP, ORAC, and SOD assays. Their findings show that the ferric ion reducing activities of the 30 plant extracts tested did not differ significantly from their DPPH and ABTS scavenging activities [38]. Additionally, Katalinic et al. (2004) [39] examined the total phenolic content and total antioxidant potential in 70 medicinal plant infusions. Their results revealed significant differences in total antioxidant capacity (FRAP) between the medicinal plant infusions, with FRAP values ranging from 59 to $25,234 \mu \mathrm{mol} \mathrm{FeII/L} \mathrm{of} \mathrm{infusion.} \mathrm{Additionally,} \mathrm{the}$ significant linear correlation between total phenolics and FRAP of medicinal plant extracts was confirmed.

\subsection{Profile of Phenolic Compounds}

Phenolic compounds are a class of natural secondary metabolites highly present in a different part of plants that has gained a lot of scientific and medicinal attention because of the wide variety of beneficial properties such as antioxidant and anti-inflammatory qualities that may be beneficial in the prevention and/or treatment of cardiovascular disease, neurological diseases, cancer, and obesity [40]. 
As can be seen in Table 3, the present study identified 13 out of 22 analyzed phenolic compounds in Lamium album flower extract obtained by $\mathrm{SC}-\mathrm{CO}_{2}$, which comprised flavones, phenylethanoid isomers and flavanone. The mean phenolic compounds concentration varied from 0.09 (trans-cinnamic acid, at $40{ }^{\circ} \mathrm{C}$ ) to $22.68 \mathrm{ng} / \mu \mathrm{L}$ (chrysin, at $50^{\circ} \mathrm{C}$ ). Apart from chrysin, high levels of concentration for extracts obtained at $50{ }^{\circ} \mathrm{C}$ have been reported for myricetin, pinostrobin, and trans-3-hydroxycinnamic acid. The concentration of the most analyzed bioactive compounds was statistically higher $(p=0.05)$ for the extract obtained at the temperature of $50{ }^{\circ} \mathrm{C}$, especially in comparison with the extraction conditions at the lower temperature of $40^{\circ} \mathrm{C}$. On the other hand, for the extraction carried out at the highest temperature $60^{\circ} \mathrm{C}$, the level of most bioactive compounds was significantly lower compared to the extraction at $50^{\circ} \mathrm{C}$, except for ritin, quercitin and trans-cinnamic acid. The obtained results are consistent with the highest antioxidant activity for the extract obtained at $50{ }^{\circ} \mathrm{C}$, confirmed by four methods (Tables 1 and 2).

Table 3. Quantitative analysis of phenolic compounds identified in Lamium album flower extract (ng/ $\mu \mathrm{L}$ extract).

\begin{tabular}{cccc}
\hline \multirow{2}{*}{ Phenolic Compounds } & \multicolumn{3}{c}{ Parameters of Extraction } \\
\cline { 2 - 4 } & $\mathbf{4 0}^{\circ} \mathbf{C}$ & $\mathbf{5 0}{ }^{\circ} \mathbf{C}$ & $\mathbf{6 0}^{\circ} \mathbf{C}$ \\
\cline { 2 - 4 } & & $\mathbf{n g} / \mathbf{\mu L}]$ \\
\hline myricetin & $6.70^{\mathrm{a}} \pm 0.46$ & $10.37^{\mathrm{b}} \pm 0.80$ & $7.61^{\mathrm{c}} \pm 0.44$ \\
quercetin & $1.89^{\mathrm{a}} \pm 0.17$ & $2.89^{\mathrm{a}} \pm 0.14$ & $1.35^{\mathrm{a}} \pm 0.28$ \\
rutin & $0.36^{\mathrm{a}} \pm 0.63$ & $2.49^{\mathrm{b}} \pm 0.17$ & $2.33^{\mathrm{b}} \pm 0.14$ \\
CAPE & $5.06^{\mathrm{a}} \pm 0.22$ & $8.72^{\mathrm{b}} \pm 0.39$ & $4.41^{\mathrm{c}} \pm 0.33$ \\
apigenin & $3.25^{\mathrm{a}} \pm 0.28$ & $6.10^{\mathrm{b}} \pm 0.14$ & $3.97^{\mathrm{c}} \pm 0.19$ \\
pinocembrin & $1.15^{\mathrm{a}} \pm 0.13$ & $1.68^{\mathrm{b}} \pm 0.23$ & $1.10^{\mathrm{a}} \pm 0.07$ \\
pinostrobin & $8.15^{\mathrm{a}} \pm 0.18$ & $13.84^{\mathrm{b}} \pm 0.29$ & $7.13^{\mathrm{c}} \pm 0.15$ \\
galangin & $5.82^{\mathrm{a}} \pm 0.33$ & $7.79^{\mathrm{b}} \pm 0.31$ & $5.07^{\mathrm{c}} \pm 0.14$ \\
chrysin & $15.75^{\mathrm{a}} \pm 1.27$ & $22.68^{\mathrm{b}} \pm 0.35$ & $13.36^{\mathrm{c}} \pm 0.45$ \\
vanillic acid & $1.96^{\mathrm{a}} \pm 0.18$ & $6.94^{\mathrm{b}} \pm 0.16$ & $4.19^{\mathrm{c}} \pm 0.36$ \\
syringic acid & $3.17^{\mathrm{a}} \pm 0.22$ & $7.81^{\mathrm{b}} \pm 0.39$ & $6.20^{\mathrm{c}} \pm 0.24$ \\
trans-3-hydroxycinnamic acid & $3.54^{\mathrm{a}} \pm 0.23$ & $9.76^{\mathrm{b}} \pm 0.35$ & $2.98^{\mathrm{c}} \pm 0.16$ \\
trans cinnamic acid & $0.09^{\mathrm{a}} \pm 0.15$ & $1.70^{\mathrm{b}} \pm 0.11$ & $1.79^{\mathrm{b}} \pm 0.13$ \\
\hline TOTAL & 80.77 & 102.79 & 61.49 \\
\hline
\end{tabular}

nd-not detected, values with the same lowercase letters in the same row indicate no significant difference at level of $5 \%(p=0.05)$.

In the literature, very little information is available concerning the phenolic compounds of the studied plant (Lamium album flowers) and their application. However, in the previous studies, some flavonoids in forms of glycosides (rutin, isoquercitrin, tyliroside) and aglycones (quercetin) and phenolic acids (protocatechuic, chlorogenic, vanillic, caffeic, coumaric, and ferulic acids) have been found in methanol and ethyl acetate extracts of L. album by using HPTLC combined with densitometry and HPLC method [8]. For the first time, Pereira et al. (2012) [5] identified derivatives of unusual flavone isoscutellarein in purified ethanol extract of flowers, leaves and stems from L. album, and were found to represent approximately one third of the total phenolics quantified and also phenylethanoid glycosides verbascoside and iso-verbascoside have been reported [5].

To the best of our knowledge, most of those phenolic compounds were identified in Lamium album for the first time in the present study. Chrysin (5,7-dihydroxyflavone) is a major compound detected in Lamium album extract in this study. It is a flavone, naturally present in flowers of various plants, honey and some mushrooms [41], it has a lot of health importance for humans. Chrysin was reported to have enormous biological activities such as antibacterial, antidiabetic, anticancer, anti-inflammatory, and anti-aging [42,43]. Furthermore, a recent clinical trial found that using chrysin can result in body weight loss and a lower postprandial blood-glucose level [41]. In addition to its medicinal use as 
an ingredient in pharmaceutical preparations, chrysin is widely utilized as a functional additive in teas, meals, and cosmetics.

Myricetin is a common plant-derived flavonoid that has also identified in the present study of Lamium album flower extract at high concentration. Myricetin is widely found in vegetables, fruits, nuts, berries, herbs, medicinal plants and beverages such as tea and wine [44]. This flavonoid has also been shown to have strong antioxidant capabilities as well as free radical scavenging properties. These activities appear to support a wide range of beneficial outcomes, including anti-platelet aggregation, antihypertensive, immunomodulatory, anti-inflammatory, anti-allergic, analgesic, and anticancer effects $[44,45]$. The rich composition of bioactive compounds of Lamium album extracts along with high antioxidant activity indicates the great potential of this poorly—so far-known plant.

\section{Conclusions}

Lamium album flowers extracts were obtained by $\mathrm{SC}-\mathrm{CO}_{2}$ with methanol as co-solvent. The antioxidant properties of the obtained extracts were estimated spectrophotometrically by using DPPH, ABTS, and FRAP assays. The findings of our study revealed that the obtained extracts from L. album flowers possess considerable antioxidant potential. The differences in antioxidant activities and total phenolic content in the extracts can be attributed to different extracting conditions, especially temperature in this study as it can have positive or negative effect on the solubility of bioactive compounds during $\mathrm{SC}-\mathrm{CO}_{2}$ extraction at constant pressure. The most efficient temperature was $50^{\circ} \mathrm{C}$. The phenolic composition of the extracts was assessed by UPLC/PDA and chrysin, pinostrobin, myricetin and trans-3-hydroxycinnamic acid were higher compared to other compounds in this study. Therefore, this work confirms that phenolic compounds and antioxidants can be effectively extracted from Lamium album flowers using green SFE technology. Our results indicate wide possibilities of using Lamium album flower extract in agriculture, food, cosmetics, and pharmaceutical industries as a source of bioactive compounds.

Author Contributions: P.A.U. and A.W. designed of the experiments; P.A.U. antioxidant activity and bioactive compounds determination; M.B. and A.W. development of analytical procedures; M.B. statistical analysis; P.A.U. manuscript preparation; M.B. and A.G.-M. reviewed the manuscript; A.W. supervision of research. All authors have read and agreed to the published version of the manuscript.

Funding: This research was funded by the Polish National Science Centre, grant number 2018/ 31/B/NZ9/03485.

Institutional Review Board Statement: Not applicable.

Informed Consent Statement: Not applicable.

Data Availability Statement: The data that support the findings of this study are available from the corresponding author, upon request.

Conflicts of Interest: The authors declare no conflict of interest.

\section{References}

1. Upadhyay, S.; Dixit, M. Role of Polyphenols and Other Phytochemicals on Molecular Signaling. Oxidative Med. Cell. Longev. 2015, 2015, 504253. [CrossRef] [PubMed]

2. Yordanova, Z.P.; Zhiponova, M.K.; Iakimova, E.T.; Dimitrova, M.A.; Kapchina-Toteva, V.M. Revealing the reviving secret of the white dead nettle (Lamium album L.). Phytochem. Rev. 2014, 13, 375-389. [CrossRef]

3. Yalçin, F.N. Ethnobotany, Pharmacology and Phytochemistry of the Genus Lamium (Lamiaceae) Bayrak Tür Polygala azizsancarii'nin Biyolojisi, Biyoçeşitliliği ve Koruması View Project PHYTOCHEMICAL AND PHARMACOLOGICAL STUDIES ON SOME PAPAVER SPECIES IN TURKEY. 2006. Available online: https://www.researchgate.net/publication/288672525 (accessed on 5 July 2021).

4. Sulborska, A.; Konarska, A.; Matysik-Woźniak, A.; Dmitruk, M.; Weryszko-Chmielewska, E.; Skalska-Kamińska, A.; Rejdak, R. Phenolic constituents of Lamium album L. subsp. album flowers: Anatomical, histochemical, and phytochemical study. Molecules 2020, 25, 6025. [CrossRef]

5. Pereira, O.R.; Domingues, M.R.M.; Silva, A.M.S.; Cardoso, S.M. Phenolic constituents of Lamium album: Focus on isoscutellarein derivatives. Food Res. Int. 2012, 48, 330-335. [CrossRef] 
6. Moskova-Doumanova, V.; Miteva, G.; Dimitrova, M.; Topouzova-Hristova, T.; Kapchina, V. Methanol and Chloroform Extracts from Lamium Album L. Affect Cell Properties of A549 Cancer Lung Cell Line. Biotechnol. Biotechnol. Equip. 2012, $26,120-125$. [CrossRef]

7. Bubueanu, C.; Gheorghe, C.; Pirvu, L.; Bubueanu, G. Antioxidant activity of butanolic extracts of Romanian native speciesLamium album and Lamium purpureum. Rom. Biotechnol. Lett. 2013, 18, 8855-8862.

8. Paduch, R.; Wójciak-Kosior, M.; Matysik, G. Investigation of biological activity of Lamii albi flos extracts. J. Ethnopharmacol. 2007, 110, 69-75. [CrossRef] [PubMed]

9. Todorov, D.; Dimitrova, M.; Shishkova, K.; Yordanova, Z.; Kapchina-Toteva, V.; Shishkov, S. Comparative anti-herpes effects of the chloroform in vitro and in vivo extracts, derived from Lamium album L. Bulg. J. Agric. Sci. 2013, 19, $190-193$.

10. Azmir, J.; Zaidul, I.S.M.; Rahman, M.M.; Sharif, K.M.; Mohamed, A.; Sahena, F.; Jahurul, M.H.A.; Ghafoor, K.; Norulaini, N.; Omar, A. Techniques for extraction of bioactive compounds from plant materials: A review. J. Food Eng. 2013, 117, 426-436. [CrossRef]

11. Smith, R.M. Before the injection-modern methods of sample preparation for separation techniques. J. Chromatogr. A 2003, 1000, 3-27. [CrossRef]

12. Benito-Román, O.; Rodríguez-Perrino, M.; Sanz, M.T.; Melgosa, R.; Beltrán, S. Supercritical carbon dioxide extraction of quinoa oil: Study of the influence of process parameters on the extraction yield and oil quality. J. Supercrit. Fluids 2018, 139, 62-71. [CrossRef]

13. Uwineza, P.A.; Waśkiewicz, A. Recent Advances in Supercritical Fluid Extraction of Natural Bioactive Compounds from Natural Plant Materials. Molecules 2020, 25, 3847. [CrossRef] [PubMed]

14. Fornari, T.; Vicente, G.; Vázquez, E.; Garcia-Risco, M.R.; Reglero, G. Isolation of essential oil from different plants and herbs by supercritical fluid extraction. J. Chromatogr. A 2012, 1250, 34-48. [CrossRef] [PubMed]

15. Gonçalves, R.M.; Lemos, C.O.T.; Leal, I.C.R.; Nakamura, C.V.; Cortez, D.A.G.; da Silva, E.A.; Cabral, V.F.; Cardozo-Filho, L. Comparing conventional and supercritical extraction of (-)-mammea A/BB and the antioxidant activity of Calophyllum brasiliense extracts. Molecules 2013, 18, 6215. [CrossRef] [PubMed]

16. Bai, X.; Aimila, A.; Aidarhan, N.; Duan, X.; Maiwulanjiang, M. Chemical constituents and biological activities of essential oil from Mentha longifolia: Effects of different extraction methods. Int. J. Food Prop. 2020, 23, 1951-1960. [CrossRef]

17. Arabshahi-Delouee, S.; Urooj, A. Antioxidant properties of various solvent extracts of mulberry (Morus indica L.) leaves. Food Chem. 2007, 102, 1233-1240. [CrossRef]

18. Li, H.-B.; Cheng, K.-W.; Wong, C.-C.; Fan, K.-W.; Chen, F.; Jiang, Y. Evaluation of antioxidant capacity and total phenolic content of different fractions of selected microalgae. Food Chem. 2007, 102, 771-776. [CrossRef]

19. Mabrouki, H.; Duarte, C.M.M.; Akretche, D.E. Estimation of total phenolic contents and in vitro antioxidant and antimicrobial activities of various solvent extracts of Melissa officinalis L. Arab. J. Sci. Eng. 2017, 43, 3349-3357. [CrossRef]

20. Moon, J.K.; Shibamoto, T. Antioxidant assays for plant and food components. J. Agric. Food Chem. 2009, 57, 1655-1666. [CrossRef]

21. Moradi, M.-T.; Karimi, A.; Alidadi, S.; Hashemi, L. In vitro anti-adenovirus activity, antioxidant potential and total phenolic compounds of Melissa officinalis L. (lemon balm) extract. Int. J. Pharmacogn. Phytochem. Res. 2016, 8, 1471-1477.

22. Re, R.; Pellegrini, N.; Proteggente, A.; Pannala, A.; Yang, M.; Rice-Evans, C. Antioxidant activity applying an improved ABTS radical cation decolorization assay. Free. Radic. Biol. Med. 1999, 26, 1231-1237. [CrossRef]

23. Xiao, F.; Xu, T.; Lu, B.; Liu, R. Guidelines for antioxidant assays for food components. Food Front. 2020, 1, 60-69. [CrossRef]

24. Benzie, I.F.F.; Devaki, M. The ferric reducing/antioxidant power (FRAP) assay for non-enzymatic antioxidant capacity: Concepts, procedures, limitations and applications. In Measurement of Antioxidant Activity \& Capacity: Recent Trends and Applications; Wily: New York, NY, USA, 2018; pp. 77-106.

25. Tomasina, F.; Carabio, C.; Celano, L.; Thomson, L. Analysis of two methods to evaluate antioxidants. Biochem. Mol. Biol. Educ. 2012, 40, 266-270. [CrossRef]

26. Espinosa-Pardo, F.A.; Nakajima, V.M.; Macedo, G.A.; Macedo, J.A.; Martínez, J. Extraction of phenolic compounds from dry and fermented orange pomace using supercritical $\mathrm{CO}_{2}$ and co-solvents. Food Bioprod. Process. 2017, 101, 1-10. [CrossRef]

27. Matkowski, A.; Piotrowska, M. Antioxidant and free radical scavenging activities of some medicinal plants from the Lamiaceae. Fitoterapia 2006, 77, 346-353. [CrossRef]

28. Grujic, S.M.; Dzamic, A.M.; Mitic, V.D.; Jovanovic, V.S.; Marin, P.D.; Stojanovic, G.S. Effects of solvent extraction system on antioxidant activity of Lamium purpureum L. Chem. Ind. 2017, 71, 361-370. [CrossRef]

29. Stanković, N.; Mihajilov-Krstev, T.; Zlatković, B.; Stankov-Jovanović, V.; Mitić, V.; Jović, J.; Čomić, L.; Kocić, B.; Bernstein, N. Antibacterial and antioxidant activity of traditional medicinal plants from the Balkan Peninsula. NJAS-Wagening. J. Life Sci. 2016, 78, 21-28. [CrossRef]

30. Prior, R.L.; Wu, X.; Schaich, K. Standardized methods for the determination of antioxidant capacity and phenolics in foods and dietary supplements. J. Agric. Food Chem. 2005, 53, 4290-4302. [CrossRef]

31. Blois, M.S. Antioxidant Determinations by the Use of a Stable Free Radical. Nat. Cell Biol. 1958, 181, 1199-1200. [CrossRef]

32. Molyneux, P. The use of the stable free radical diphenylpicryl-hydrazyl (DPPH) for estimating antioxidant activity. Songklanakarin. J. Sci. Technol. 2004, 26, 211-219.

33. Ho, K.Y.; Tsai, C.C.; Chen, C.P.; Huang, J.S.; Lin, C.C. Screening of Brazilian plant extracts for antioxidant activity by the use of DPPH free radical method. Phyther. Res. 2001, 15, 127-130. 
34. Bursal, E.; Gülçin, I. Polyphenol contents and in vitro antioxidant activities of lyophilised aqueous extract of kiwifruit (Actinidia deliciosa). Food Res. Int. 2011, 44, 1482-1489. [CrossRef]

35. Trouillas, P.; Calliste, C.-A.; Allais, D.-P.; Simon, A.; Marfak, A.; Delage, C.; Duroux, J.-L. Antioxidant, anti-inflammatory and antiproliferative properties of sixteen water plant extracts used in the Limousin countryside as herbal teas. Food Chem. 2003, 80, 399-407. [CrossRef]

36. Miller, N.J.; Rice-Evans, C.A. Spectrophotometric determination of antioxidant activity. Redox Rep. 1996, 2, 161-171. [CrossRef]

37. Fernandes, R.P.P.; Trindade, M.A.; Tonin, F.G.; Lima, C.G.; Pugine, S.M.P.; Munekata, P.E.S.; Lorenzo, J.M.; De Melo, M.P. Evaluation of antioxidant capacity of 13 plant extracts by three different methods: Cluster analyses applied for selection of the natural extracts with higher antioxidant capacity to replace synthetic antioxidant in lamb burgers. J. Food Sci. Technol. 2015, 53, 451-460. [CrossRef]

38. Dudonné, S.; Vitrac, X.; Coutière, P.; Woillez, M.; Mérillon, J.-M. Comparative study of antioxidant properties and total phenolic content of 30 plant extracts of industrial interest using DPPH, ABTS, FRAP, SOD, and ORAC assays. J. Agric. Food Chem. 2009, 57, 1768-1774. [CrossRef]

39. Katalinic, V.; Milos, M.; Kulisic, T.; Jukic, M. Screening of 70 medicinal plant extracts for antioxidant capacity and total phenols. Food Chem. 2006, 94, 550-557. [CrossRef]

40. Cory, H.; Passarelli, S.; Szeto, J.; Tamez, M.; Mattei, J. The role of polyphenols in human health and food systems: A mini-review. Front. Nutr. 2018, 5, 87. [CrossRef] [PubMed]

41. Anand, K.V.; Anandhi, R.; Pakkiyaraj, M.; Geraldine, P. Protective effect of chrysin on carbon tetrachloride $\left(\mathrm{CCl}_{4}\right)$-induced tissue injury in male Wistar rats. Toxicol. Ind. Health 2011, 27, 923-933. [CrossRef] [PubMed]

42. Souza, L.C.; Antunes, M.S.; Filho, C.B.; Del Fabbro, L.D.; de Gomes, M.G.; Goes, A.T.R.; Donato, F.; Prigol, M.; Boeira, S.P.; Jesse, C.R. Flavonoid Chrysin prevents age-related cognitive decline via attenuation of oxidative stress and modulation of BDNF levels in aged mouse brain. Pharmacol. Biochem. Behav. 2015, 134, 22-30. [CrossRef] [PubMed]

43. Mani, R.; Natesan, V. Chrysin: Sources, beneficial pharmacological activities, and molecular mechanism of action. Phytochemistry 2018, 145, 187-196. [CrossRef] [PubMed]

44. Semwal, D.K.; Semwal, R.B.; Combrinck, S.; Viljoen, A. Myricetin: A dietary molecule with diverse biological activities. Nutrients 2016, 8, 90. [CrossRef] [PubMed]

45. Taheri, Y.; Suleria, H.A.R.; Martins, N.; Sytar, O.; Beyatli, A.; Yeskaliyeva, B.; Seitimova, G.; Salehi, B.; Semwal, P.; Painuli, S.; et al. Myricetin bioactive effects: Moving from preclinical evidence to potential clinical applications. BMC Complement. Med. Ther. 2020, 20, 20-24. [CrossRef] [PubMed] 